\title{
Effect of ram introduction on the oestrous cycle of springbok ewes (Antidorcas marsupialis)
}

\author{
D. C. Skinner ${ }^{1}$, S. D. Cilliers ${ }^{2}$ and J. D. Skinner ${ }^{2}$ \\ ${ }^{1}$ Department of Zoology and Physiology, University of Wyoming, PO Box 3166, Laramie, \\ WY 82071-3166, USA; and ${ }^{2}$ Wildlife Unit, Faculty of Veterinary Science, University of \\ Pretoria, Onderstepoort, 0110, South Africa
}

\begin{abstract}
Springbok are aseasonally breeding wild ungulates that inhabit arid environments, and interest has been shown in domesticating them for agricultural purposes. The present study was conducted for husbandry purposes to determine the effect of introducing a vasectomized ram to an isolated herd of springbok ewes $(n=9)$. Blood was collected from ewes every third day, before and after introduction of a vasectomized ram. Ewes were subjected to the ram for 42 days. Plasma progesterone was measured by radioimmunoassay and was used to establish the stage of the oestrous cycle. After introduction of the ram, the variation in the timing of the follicular phase between ewes was
\end{abstract}

clearly reduced, compressing the spread of oestrus in the springbok ewes from 11 to 3 days. In seven of the nine ewes, the ram was introduced during the luteal phase of the oestrous cycle, causing this cycle to be significantly longer in duration $(P<0.05)$ and to have a higher maximum concentration of progesterone $(P<0.001)$ than cycles before and after introduction of the ram. This finding implies that the mechanism of synchronization operates through a luteotrophic effect. These results indicate that rams may be used successfully to synchronize breeding in springbok.

\section{Introduction}

Springbok are antelopes that are adapted to an arid environment and inhabit the desert and semi-desert regions of southern Africa. As they thrive in these sparsely vegetated areas, springbok are of potential agricultural importance and may be domesticated in future. Springbok are considered opportunistic breeders and have an undefined breeding season; oestrous cycles continue unabated in some individuals, whereas in others there is a clear anoestrous phase but with an irregular onset and cessation (Skinner et al., 2001). In the wild, springbok may mate throughout the year if physiological and environmental conditions are optimal for their energy requirements (Skinner and Louw, 1996).

Depending on resource availability, rams remain territorial throughout the year, defending territorial resources to attract females, as only territorial males mate. Territorial males may rut for various periods at any time of the year, and the rut is activated by an unknown proximate factor. It has been suggested that rutting induces anoestrous ewes to come into oestrus, synchronizing conceptions and later births (Skinner and Louw, 1996). Furthermore, Skinner et al. (1996) suggest that there could be at least two proximate stimuli, one initiating rutting behaviour in the male and a second initiating oestrus.

Heap (1901) was the first to suggest that the presence of a male influences the onset of oestrus in females. In sheep, a ram introduced to a ewe in anoestrus will stimulate the

Email: dcs@uwyo.edu neuroendocrine reproductive axis and, thereby, ovulation (Knight, 1983). In the seasonally breeding blesbok, Damaliscus pygargus, plasma progesterone concentration in anoestrous ewes increased within a week of a ram being introduced, and synchronous cycles were achieved a month (two cycles) later (Marais and Skinner, 1993).

To the authors' knowledge, there are no published reports that the presence of males affects oestrus and ovulation in aseasonally breeding wild ungulates, and the effect of males on cyclic female ungulates remains unclear. The aim of the present study was to assess whether the ram plays any role in the reproductive adaptation of the cyclic aseasonal and opportunistic-breeding springbok ewe.

\section{Materials and Methods}

Adult springbok ewes ( $n=9 ; 2.5$ years), which were all showing oestrous cycles and had all been housed together for over 2 years (Skinner et al., 2001), were randomly divided into two groups. These groups were placed in separate paddocks $1700 \mathrm{~m}$ apart. A vasectomized springbok ram was introduced to one group for 42 days and then moved to the second group for 42 days. This duration would have allowed for detection of two full oestrous cycles (Skinner et al., 2001). Animals were fed each day on alfalfa, cottonseed and antelope pellets (Epol Ltd, Pretoria) and had free access to water. It was not determined whether the vasectomized ram mated with the ewes during the study. All animal procedures were approved by the Animal Ethics Committee of the University of Pretoria. 
Ewes were blindfolded and physically restrained by two persons for blood sampling. Blood was taken from the jugular vein, collected in heparinized venoject tubes (Becton Dickinson, Meylen) and kept on ice until centrifuged (1500 g at $\left.4^{\circ} \mathrm{C}\right) 30$ min later. Plasma was decanted and frozen at $-20^{\circ} \mathrm{C}$ for later radioimmunoassay. Blood sampling commenced 60 days before ram introduction (group 1: 3 June; group 2: 18 July) and samples were taken, on average, every third day between 08:00 $\mathrm{h}$ and 10:00 $\mathrm{h}$ for the duration of the experiment. Different clothing, boots and blindfold were used in each enclosure to avoid transmitting any odours between enclosures.

After extraction from plasma, concentrations of progesterone determined in triplicate using a single radioimmunoassay (Saumande et al., 1985). The intra-assay coefficient of variation was $10 \%$ and assay sensitivity was $0.05 \mathrm{ng} \mathrm{ml}^{-1}$. The standard in both progesterone assays was pure progesterone (Steraloids Inc., Newport, RI).

The onset of the luteal phase was taken as the time at which the concentration of progesterone in a sample exceeded $1.5 \mathrm{ng} \mathrm{ml}^{-1}$. Data for all ewes were plotted as the percentage of ewes in the follicular phase. The chi-squared test was used to determine the deviation of the percentage of ewes in the follicular phase from the expected random percentage $(23 \%)$. The synchronization that had occurred was evaluated further by calculating the cumulative percentage of ewes that were synchronous in 0,4 or 7 days (within 10 days all ewes were in the follicular phase of an oestrous cycle) for each oestrous cycle, and the means for each period before and after introduction of the ram were compared using Student's $t$ test.

It was apparent that seven of the nine ewes were in the luteal phase at the time the ram was introduced and the remaining two ewes were in the follicular phase. Thus, for statistical analysis of the effect of the ram on the duration of the oestrous cycle and the maximum progesterone concentration of the luteal phase, only data from the seven ewes that were in the luteal phase at the time the ram was introduced were compared. The duration of the oestrous cycle was calculated as the period from the time the first sample of one luteal phase exceeded $1.5 \mathrm{ng}$ progesterone $\mathrm{ml}^{-1}$ to the time the first sample of the next luteal phase exceeded $1.5 \mathrm{ng}$ progesterone $\mathrm{ml}^{-1}$. The average duration of the oestrous cycle and maximum concentration of progesterone of all the luteal phases before (3-4) and after (2) introduction of the ram were calculated for each ewe. These averages before and after introduction of the ram were compared with the cycle in which the ram was introduced, using one-way repeated measures ANOVA, with Bonferonni post-hoc analysis.

\section{Results}

Before the introduction of the vasectomized ram, there was no synchrony in the follicular phase among individual springbok ewes (Fig. 1) and the distribution of ewes in the follicular phase was uniform (day -60 to day $0: \chi^{2}=16.07$,
$P>0.4)$. However, the ram clearly induced synchronicity in the follicular phase after its introduction (day 0 to day 42; $\left.\chi^{2}=103.82, \quad P<0.0001\right)$. Comparison of the average cumulative percentage of ewes in the follicular phase of the oestrous cycle both before and after introduction of the ram provided further evidence that significant synchronization had been induced by the ram (Fig. 1b).

Seven of the nine springbok ewes were in the luteal phase at the time the ram was introduced and, in these ewes, there was a significant increase $(P<0.01)$ in the duration of that oestrous cycle (Figs $2 \mathrm{a}$ and $3 \mathrm{~b}$ ). The duration of the oestrous cycle before and after introduction of the ram was not significantly different and the mean oestrous cycle duration ( $16.1 \pm 0.6$ days) was similar to that previously reported for this group of ewes (16.4 \pm 0.4 days; Skinner et al., 2001). In these seven ewes, the maximum concentration of progesterone in the luteal phase in which the ram was introduced was also significantly $(P<0.0001)$ higher than the mean maximum concentrations of progesterone in the luteal phases before and after introduction of the ram (Figs 2a and 3a). The maximum concentration of progesterone of the luteal phase before and after introduction of the ram were not significantly different.

In the remaining two ewes (Fig. 2b), which were in the follicular phase at the time the ram was introduced, introduction of the ram did not appear to affect the duration of the oestrous cycle or the amplitude of the subsequent luteal phase, although these data were not statistically analysed on account of the small sample size.

\section{Discussion}

To the authors' knowledge, this is the first study to investigate the effect of introducing a ram to wild ungulates that are already in the breeding season. The effect in springbok was clear: the ram synchronized ovulation in the ewes within two oestrous cycles. The effect appeared to occur primarily through a luteotrophic mechanism, as both the duration of the oestrous cycle and the amplitude of the luteal phase in which the ram was introduced were significantly increased.

The present results concur with two earlier studies investigating this phenomenon in domesticated ungulates (Ngere and Dzakuma, 1975; Chemineau, 1983). Nungua black head and West African dwarf sheep are thought to exhibit oestrous cycles throughout the year, and the introduction of rams to ewes previously held in isolation from rams led to a significant increase in the percentage mated within a day of being introduced. Similarly, Chemineau (1983) reported that in creole goats, 65\% of the females showing oestrous cycles were in oestrus within 3 days after the introduction of the male. However, neither of these studies (Ngere and Dzakuma, 1975; Chemineau, 1983) investigated the effect of the male on individual females and, more importantly, the period immediately preceding the introduction of the male was not studied. As noted by Chemineau (1983), it was possible that synchronization in 


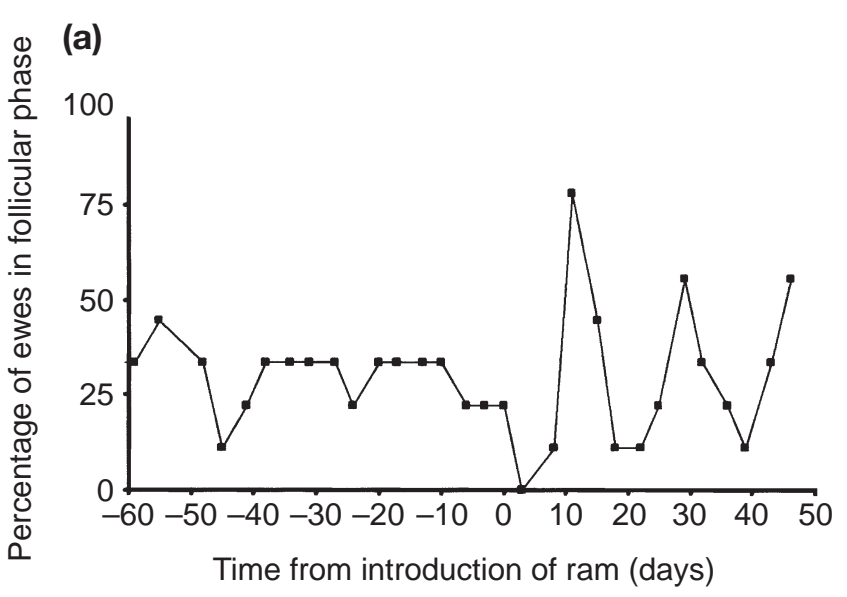

(b)

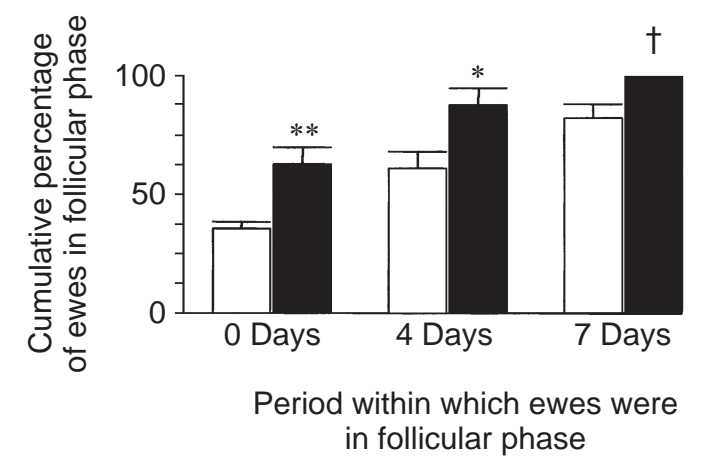

Fig. 1. Effect of introduction of a ram on oestrous cycles in springbok ewes $(n=9)$. (a) Data from all ewes plotted as a function of the percentage in the follicular phase in relation to the time the ram was introduced. Before the introduction of the ram, there was no difference in the percentage of ewes in the follicular phase from the expected percentage (day -60 to day $0: \chi^{2}=16.07, P>0.4$ ). In contrast, the ram significantly synchronized the oestrous cycles of the springbok ewes (day 0 to day 42: $\chi^{2}=103.82, P<0.0001$ ). (b) The percentage of ewes in the follicular phase within a specific period was significantly less before introduction of the ram ( $\square$ ) compared with after introduction of the ram $(\mathbf{\square}) .{ }^{*} P<0.05$; ${ }^{* *} P<0.01 ;{ }^{+} P=0.055$.

these studies occurred before the introduction of the male. In the present study in springbok, there was no synchronization in the follicular phases before the introduction of the ram.

Synchronized cycles have also been reported in several studies of rodents. In laboratory mice, exposure to males, and specifically their urine, has been shown to synchronize mating (for a review, see McClintock, 1983). In the Djungarian hamster, Phodopus campbelli, mating was observed in over $50 \%$ of virgin females 3 days after pairing with males (Erb et al., 1993). In contrast, no effect of the presence of a male on oestrous cycle synchrony was reported in the white-footed mouse, Peromyscus leucopus (Yasukawa et al., 1978). In woolly opossums, Caluromys philander, the introduction of a male also synchronizes oestrous cycles (Perret and Ben M'Barek, 1991).
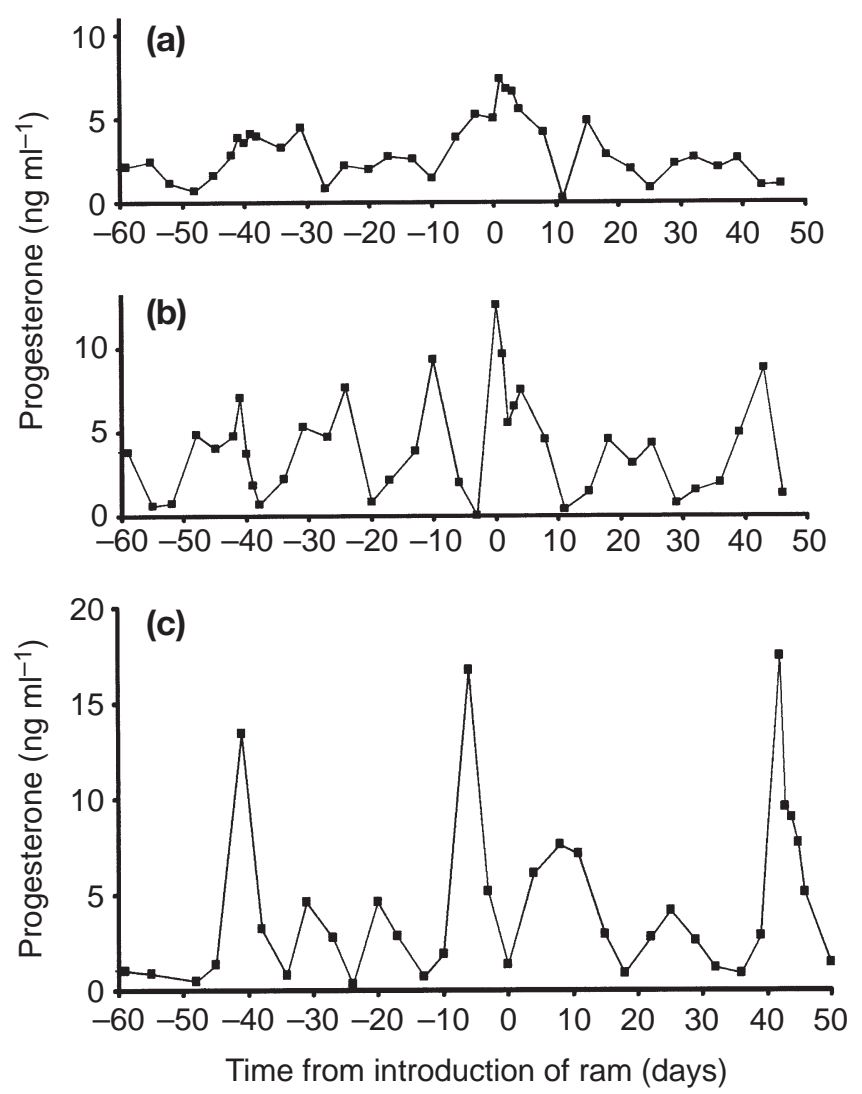

Fig. 2. Individual progesterone profiles from three of the nine ewes studied. $(a, b)$ Representative profiles from two of the seven ewes, which were in the luteal phase when the ram was introduced. Note that in (b), the duration of the oestrous cycle is only slightly longer and may indicate that early in the luteal phase the effect of introducing the ram is smaller than it is later in the luteal phase. (c) Profile from one of the two remaining ewes that were in the follicular phase when the ram was introduced.

However, there is much controversy over the occurrence and importance of oestrous and menstrual cycle synchronization (Schank, 2001a,b) and, in this context, some caution is needed in the interpretation of the present data. Most notably, was the synchrony observed in the present study random? Although this possibility cannot be discounted unequivocally, it is unlikely. First, there was no evidence of synchrony before the study, and retrospective analysis of data from bi-weekly samples over 2 years from the same ewes (Skinner et al., 2001) revealed no evidence of synchrony. These data support the hypothesis (Schank, 2000) that oestrous cycles in springbok are not synchronized in the absence of males. Second, the duration of the oestrous cycle and the amplitude of the luteal phase in which the ram was introduced were clearly increased in the presence of the ram. This finding indicates that introduction of the ram affects some physiological factor or factors in the ewe, the identity of which remains to be determined. The results of the present study imply that a major effect of this factor is luteotrophic. One effect of pheromones in rodent 
(a)

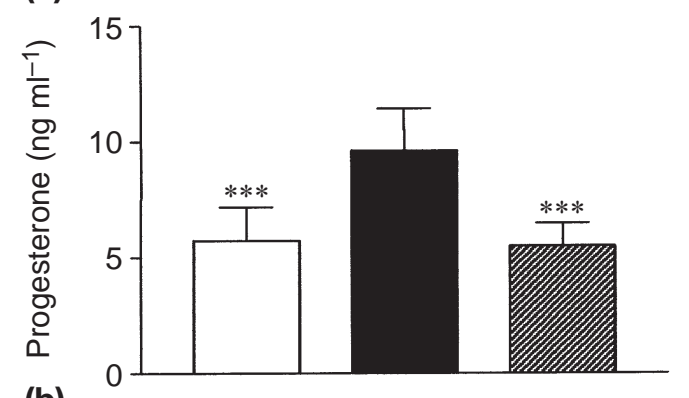

(b)

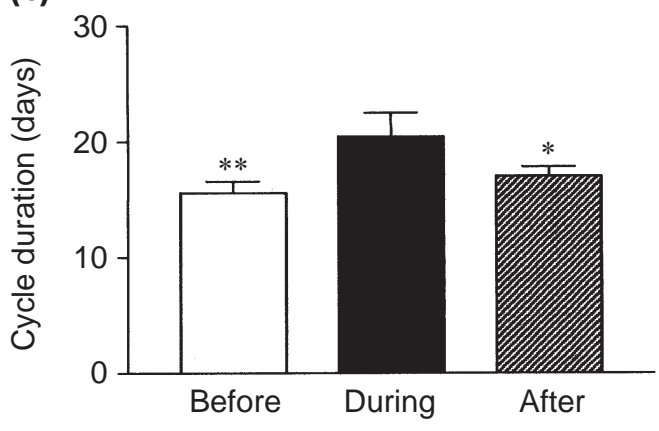

Period relative to introduction of ram

Fig. 3. Effect of introduction of a ram on the duration of the oestrous cycle and maximum concentration of progesterone of luteal phase in ewes $(n=7)$ that were in the luteal phase of the oestrous cycle. The ram was left in the pen after its introduction. (a) The average duration of the oestrous cycle before or after the introduction of the ram was compared with the duration of the oestrous at the time of introduction of the ram. (b) The average maxima of the luteal phases before and after the introduction of the ram were compared with the maximum of the luteal phase at the time of the introduction of the ram. ${ }^{*} P<0.05$; ${ }^{* *} P<0.01$; ${ }^{* * *} P<0.001$ compared with the oestrous cycle during which the ram was introduced.

studies is luteotrophic (Mody, 1963; Champlin, 1971). In woolly opossums, both luteolytic and luteotrophic effects have been reported after introduction of a male (Perret and Ben M'Barek, 1991). Specifically, if a male woolly opossum was introduced in the luteal phase, the duration of that phase was significantly reduced, whereas if the female was in the follicular phase, the duration of that phase was lengthened. In goats, Chemineau (1983) speculated that the synchronization induced in female goats by males was due to a luteolytic mechanism. Whether pheromones (Pfaus and Heeb, 1997; Rekwot et al., 2001) or behavioural input from the ram or stress (Tilbrook et al., 2000) induced by the introduction of the ram were the causative factors in synchronizing oestrous cycles in the present study was not determined and warrants further investigation.

Although the effect of the male on anoestrous females is well documented in ungulates (for a review, see Rekwot et al., 2001), there is a paucity of data on the endocrine response after the introduction of a ram to females already exhibiting oestrous cycles. Estes (1976) first speculated that synchronizing births in wild ungulates was important in predator-prey relationships, ensuring that predators were exposed to large numbers of neonates at a time when the latter were most vulnerable. It was assumed that the effect of proximate factors such as daylength on the seasonally breeding anoestrous female was enhanced by the effect of the male, to ensure that births were even more concentrated. Conversely, antelope adapted to the desert breed aseasonally. This pattern has evolved to cope with the vagaries of a desert climate (Skinner and Skinner, 2001). Nevertheless, births of springbok lambs in the wild occur in pulses (Skinner and Louw, 1996), again, probably in an attempt to inundate potential predators with prey, although predator populations are sparse in desert biomes. The present study may help to explain the role of the male in the occurrence of these pulses in the pattern of births in springbok.

The authors thank Martin Haupt and Dominic Moss for considerable assistance with animal husbandry and collecting blood samples; they made this project possible.

\section{References}

Champlin AK (1971) Suppression of oestrus in grouped mice: the effects of various densities and the possible nature of the stimulus Journal of Reproduction and Fertility 27 233-241

Chemineau P (1983) Effect on oestrus and ovulation of exposing creole goats to the male at three times of the year Journal of Reproduction and Fertility 67 65-72

Erb GE, Edwards HE, Jenkins KL, Mucklow LC and Wynne-Edwards KE (1993) Induced components in the spontaneous ovulatory cycle of the Djungarian hamster (Phodopus campbelli) Physiology and Behavior 54 955-959

Estes RD (1976) The significance of breeding synchrony in the wildebeest East African Wildlife Journal 14 135-142

Heap W (1901) Sexual season in mammals Quarterly Journal of Microscopy Science 44 1-70

Knight TW (1983) Ram induced stimulation of ovarian and oestrous activity in anoestrous ewes - a review Proceedings of the New Zealand Society for Animal Production 43 7-11

McClintock MK (1983) Pheromonal regulation of the ovarian cycle: enhancement, suppression and synchrony. In Pheromones and Reproduction in Mammals pp 113-149 Ed. JG Vandenbergh. Academic Press, New York

Marais AL and Skinner JD (1993) The effect of the ram in synchronisation of oestrus in blesbok ewes (Damaliscus dorcas phillipsi) African Journal of Ecology 31 255-260

Mody JK (1963) Structural changes in the ovaries of IF mice due to age and various other states: demonstration of spontaneous pseudopregnancy in grouped virgins Anatomical Record 145 439-447

Ngere LO and Dzakuma JM (1975) The effect of sudden introduction of rams on oestrus pattern of tropical ewes Journal of Agricultural Science (Cambridge) 84 263-264

Perret M and Ben M'Barek S (1991) Male influence on oestrous cycles in female woolly opossum (Caluromys philander) Journal of Reproduction and Fertility $\mathbf{9 1}$ 557-566

Pfaus JG and Heeb MM (1997) Implications of immediate-early gene induction in the brain following sexual stimulation of female and male rodents Brain Research Bulletin 44 397-407

Rekwot PI, Ogwu D, Oyedipe EO and Sekoni VO (2001) The role of pheromones and biostimulation in animal reproduction Animal Reproduction Science 65 157-170

Saumande J, Tamboura D and Chupin D (1985) Changes in milk and plasma concentration of progesterone in cows after treatment to induce 
superovulation and their relationship with the number of ovulations and embryos collected Theriogenology 23 719-731

Schank JC (2000) Menstrual-cycle variability and measurement: further cause for doubt Psychoneuroendocrinology 25 837-847

Schank JC (2001a) Measurement and cycle variability: reexamining the case for ovarian-cycle synchrony in primates Behavioral Processes 56 131-146

Schank JC (2001b) Menstrual-cycle synchrony: problems and new directions for research Journal of Comparative Psychology 115 3-15

Skinner DC, Richter TA, Malpaux B and Skinner JD (2001) Annual ovarian cycles in an aseasonal breeder, the springbok (Antidorcas marsupialis) Biology of Reproduction 64 1176-1182

Skinner JD and Louw GN (1996) The Springbok Transvaal Museum Monograph, Transvaal Museum, Pretoria

Skinner JD and Skinner DC (2001) Significance of aseasonal breeding in arid adapted antelope in Southern Africa. In Ecology of Desert Environments pp 391-403 Ed. I Prakash. Scientific Publishers (India), Jodhpur
Skinner JD, van Aarde RJ, Knight MH and Dott HM (1996) Morphometrics and reproduction in a population of springbok, Antidorcas marsupialis, in the semi-arid southern Kalahari African Journal of Ecology 34 312-330

Tilbrook AJ, Turner Al and Clarke IJ (2000) Effects of stress on reproduction in non-rodent mammals: the role of glucocorticoids and sex differences Reviews in Reproduction 5 105-113

Yasukawa N, Michael SD and Christian JJ (1978) Estrous cycle regulation in the whitefooted mouse (Peromyscus leucopus) with special reference to vaginal cast formation Laboratory Animal Science 28 46-50

Received 24 April 2002.

First decision 27 May 2002.

Revised manuscript received 7 June 2002.

Accepted 19 June 2002. 